\title{
Vulnerability of Paleosol Carbon Decomposition to Root-Derived Carbon Inputs
}

\author{
Marie-Anne de Graaff ${ }^{1}$,Abby McMurtry ${ }^{1}$, Laura
}

Szymanski ${ }^{2}$, Manisha Dolui ${ }^{3}$, Jennifer Pett-Ridge ${ }^{4}$, Asmeret Asefaw Berhe ${ }^{3}$, Joe Mason², Erika MarìnSpiotta $^{2}$

${ }^{1}$ Boise State University, ID, USA (*Correspondence: marie-annedegraaff@boisestate.edu)

${ }^{2}$ University of Wisconsin Madison, WI, USA (marinspiotta@wisc.edu)

${ }^{3}$ University of California Merced, CA, USA (aaberhe@ucmerced.edu)

${ }^{4}$ Lawerence Livermore National Lab, CA, USA (pettridge2@1ln1.gov)

Buried paleosols can store a significant amount of carbon (C), and understanding the processes influencing its turnover is critical for predicting the response of this $\mathrm{C}$ pool to environmental change and feedbacks to climate. Persistence of paleosol $\mathrm{C}$ is favored by burial which limits plant derived $\mathrm{C}$ inputs and microbial activity. However, resurfacing of buried soil due to erosion will increase influx of root-derived $\mathrm{C}$ which may leave paleosol $\mathrm{C}$ vulnerable to decomposition. With this study we aim to evaluate how root-derived $\mathrm{C}$ inputs affect decomposition of paleosol $\mathrm{C}$ along varying degrees of isolation from modern surface conditions. Our study site is located in the U.S. Great Plains (Wauneta, NE), where climate-driven loess deposition during the late Pleistocene and Holocene resulted in sequences of buried soils in thick loess deposits. Erosion has created toposequences across the landscape, where the paleosol exists at varying degrees of isolation from the modern landscape.We collected Brady soil from $0.2 \mathrm{~m}, 0.4 \mathrm{~m}$, and $1.2 \mathrm{~m}$ below the modern surface and conducted two controlled laboratory incubations in airtight mesocosms. Soils were amended with (1) a lab synthesized ${ }^{13} \mathrm{C}$ labeled $\left(12\right.$ atom $\%{ }^{13} \mathrm{C}$ ) solution to mimic root exudates $\left(0.3 \mathrm{mg} \mathrm{C} \mathrm{g}^{-1}\right.$ soil) and (2) root litter enriched to 92atom $\%{ }^{13} \mathrm{C}$ (0.3 $\mathrm{mg} \mathrm{C} \mathrm{g}^{-1}$ soil) in 14-day and 240-day incubations, respectively. We quantified microbial $\mathrm{CO}_{2}$ respiration, and used the ${ }^{13} \mathrm{C}$ isotopic signature of respired $\mathrm{CO}_{2}$ to partition between root, and Brady soil derived $\mathrm{C}$ decomposition. Microbial C use efficiency was also measured using both root litter and exudate amendments. Our data indicate that Brady soil $\mathrm{C}$ is highly vulnerable to decomposition with the addition of root-derived $\mathrm{C}$ regardless of burial depth. Thus increased exposure of Brady soil $\mathrm{C}$ to modern surface conditions will enhance Brady-C decomposition across the soil profile. 